\title{
People who survived their death. Advice for medical professionals based on the analysis of published cases worldwide
}

\author{
Małgorzata Grześkowiak', Agnieszka D Gaczkowska ${ }^{1,2}$, Artur Bekała', Krzysztof Pietrzkiewicz' , \\ Piotr Rzeźniczek', Marta Iwańska' , Anna Kluzik¹,2, Paweł Sobczyński ${ }^{3}$ Krzysztof Kusza² , Zsolt Molnar2,4
}

'Department of Teaching Anesthesiology and Intensive Therapy, University of Medical Sciences Poznań, Poznań, Poland 2Department of Anesthesiology, Intensive Therapy and Pain Treatment, University of Medical Sciences, Poznań, Poland ${ }^{3} 1^{\text {st }}$ Department of Anesthesiology and Intensive Therapy, University of Medical Sciences, Poznań, Poland ${ }^{4}$ Center for Translational Medicine, Medical School, University of Pécs, Pécs, Hungary

Correspondence to: Agnieszka Gaczkowska, MD, PhD, Department of Teaching Anesthesiology and Intensive Therapy,

University of Medical Sciences, Marii Magdaleny 14,

61-861 Poznań, Poland phone: +48616687836, e-mail: agaczkowska@ump.edu.pl Copyright by the Author(s), 2021 Kardiol Pol. 2021; 79 (12): 1375-1377; DOI: 10.33963/KP.a2021.0170 Received: May 6, 2021 Revision accepted: December 5, 2021 Published online: December 5, 2021

\section{INTRODUCTION}

Autoresuscitation stands for a phenomenon in which the heart can spontaneously resume electrical and mechanical function generating blood flow after cardiac arrest [1] following either unsuccessful cardiopulmonary resuscitation or in cases when resuscitation attempts were not undertaken. The recovery of cardiac function after discontinued cardiopulmonary resuscitation (CPR) was reported for the first time by Linko et al. in 1982 [2], and the term "Lazarus phenomenon" was introduced by Bray in 1993 [3]. According to published reports, autoresuscitation may be associated with various conditions such as hyperinflation, myocardial stunning, hyperkalemia, delayed action of drugs, or absence of minimal vital signs [4]. Available systematic reviews lack the data on the medical conditions of the victims, which potentially could lead to clinical death. We were unable to find any reports presenting causes of cardiac arrest or diseases in patients experiencing autoresuscitation. Also, the issue of heart rhythm recorded before stopping CPR and its influence on autoresuscitation has not been adequately addressed. Therefore, our study aimed to fill this gap in knowledge by analyzing all published cases of the Lazarus phenomenon and trying to identify the most relevant factors that may facilitate autoresuscitation and survival.

\section{METHODS}

The systematic review was performed by using the preferred reporting items for systematic review and meta-analysis statement (PRISMA). We used the classical PICO format for our clinical question.

The following four electronic databases were searched for reports published before December 31 ${ }^{\text {st }}, 2018$ : PubMed, Clinical Key, Scopus, and Web of Science. The phrases used in our research were: "Lazarus phenomenon" or "Lazarus or phenomenon", "Lazarus syndrome or Lazarus or syndrome", and "autoresuscitation or auto-resuscitation". We included reports in English, German, and Spanish. Each database was independently reviewed by two members of the research team, and results were compared. Citations from each database were downloaded into a citation manager, and two reviewers removed duplicated records.

The Shapiro-Wilk test was used to assess conformity with a normal distribution. Numerical variables were presented as median with interquartile range (IQR) and compared between groups using the Mann-Whitney $\mathrm{U}$ test. Categorical variables were reported as absolute numbers and percentages and compared using Pearson's chi-squared test or Fisher's exact test. Association between numerical variables was assessed by Spear- 
man's correlation. All analyses were performed in Statistica 12 (StatSoft Inc., Tulsa, OK, USA). Statistical significance was defined as $P<0.05$. The approval by the institutional review board or ethics committee was not required.

\section{RESULTS AND DISCUSSION}

Initially, 1694 records in the four databases met the search criteria. After the duplicates were removed and 1621 articles were screened, 55 reports were found relevant for the analysis. Overall, 66 individual cases were analyzed (Supplementary material, Table S1). The included reports came from 24 countries.

For statistical analysis depending on various variables, only well-documented cases were used. Survival of patients experiencing in- and out-of-hospital cardiac arrest and caused by cardiac or non-cardiac conditions was compared. In most cases, cardiac arrest was not of cardiac origin ( $n=18 / 30$ ). No significant differences were found when comparing subgroups according to sex $(11.43 \%$ vs. $17.39 \% ; P=0.70)$ and cardiac rhythm (33.33\% vs. $14.29 \%$; $P=0.17$ ). Survival time was longer in patients who regained consciousness after autoresuscitation ( $n=15$; median, 15.00; $\min , 0.00$, max; 93.00 min; QR, 9.00-57.00) compared to unconscious patients ( $n=28$, median, 0.00; $\min , 0.00$; max, 135.00 min; IQR, 0.00-4.00 min; $P=0.005$ ). Regaining consciousness was not synonymous with full logical contact without neurological deficits. The duration of CPR significantly correlated with the time of survival $(R=0.41$; $P=0.003$ ), indicating that the longer was the CPR time, the longer was survival.

Reports on the Lazarus phenomenon are not abundant. Hornby K et al. [5] and Hornby L et al. [6], presented a systematic review on autoresuscitation in 2010, updated in 2018. The review of cases of the Lazarus phenomenon in German-speaking countries was also presented by Herff et al. in 2010 [7]. Sheth et al. [8] analyzed cases of autoresuscitation between 2000 and 2008 in patients considered for organ donation and proposed that there should be 2 minutes of observation after completion of CPR. If no autoresuscitation occurs, this time is sufficient to declare death, even in patients under 18 years old [8].

Our systematic review of case reports on the Lazarus phenomenon revealed a significant correlation between the duration of CPR and the length of survival. Additionally, we found that survival occurred more frequently in those patients who had been resuscitated longer. Based on our data, it seems that the longer CPR, the more common the occurrence of outliving. The duration of CPR in our cohort of 66 cases chosen for analysis was similar to that reported in a recent 2-year survey of in-hospital cardiac arrests by Yilmaz et al. [9]. These data suggest that CPR should be continued for at least 30 minutes to be most efficient.

One of the most important prognostic features is the cause of cardiac arrest. Hyperkalemia and hypovolemia are reversible causes and should be treated immediately when confirmed. Patients with drug overdose or poisoning who receive an antidote may need longer CPR administration until antidote works, which is consistent with the principles of dealing with reversible cardiovascular causes [10]. Also, hypovolemia caused by bleeding requires a supply of fluids and an extended waiting time for the therapeutic effect [11]. The delayed action of medication injected into peripheral veins may also be responsible for the Lazarus phenomenon. Therefore, the authors suggested administering medications during CPR intraosseous or to a central line instead of peripherally [4]. To exclude the possibility that minimal vital signs go undetected with physical examination, more advanced methods should be used e.g. echocardiography [4]. Updated resuscitation guidelines (ERC 2015/AHA 2015) take into consideration these issues and recommend using advanced diagnostic techniques.

The majority (79\%) of patients with autoresuscitation presented non-shockable rhythm during CPR before autoresuscitation. It is well known that survival rate is better for shockable rhythms, and it may be the case that when the shockable rhythm is present, CPR is being continued longer as compared to non-shockable cases [12]. For clinical practice, patients should be monitored longer for non-shockable rhythms after withdrawal from resuscitation.

In the presented analysis, 34 patients experienced out-of-hospital cardiac arrests (OHCA) and only 9 in-hospital cardiac arrests (IHCA). We did not find any significant differences in survival in IHCA and OHCA ( $P=0.69)$. A hospital in Hiroshima presented a report suggesting that using extracorporeal life support (ECLS) is superior in patients after IHCA than OHCA. This advantage, however, disappears after adjusting for patient-related factors and the time delay in starting ECLS [13].

Interestingly, no significant correlation between the duration of CPR, achieving the complete autoresuscitation, and restoration of all neurological functions was found. Based on our analysis, we can conclude there is no indication as to when the length of CPR results in an unfavorable outcome. In many cases, the time between the end of CPR and the beginning autoresuscitation was too long, and stopping CPR led to irreversible brain damage [14].

Autoresuscitation is rare but should be kept in mind before a patient is presumed dead. It can occur regardless of the cause and place of the cardiac arrest. The presence of non-shockable heart rhythm during CPR does not preclude autoresuscitation. Prolonged CPR (at least 30 minutes) increases the patient's chance of survival. In OHCA cases, we should also always consider starting extended cardiopulmonary resuscitation with extracorporeal membrane oxygenation [15].

\section{Supplementary material}

Supplementary material is available at https://journals. viamedica.pl/kardiologia_polska. 


\section{Article information}

Conflict of interest: None declared.

Open access: This article is available in open access under Creative Common Attribution-Non-Commercial-No Derivatives 4.0 International (CC BY-NC-ND 4.0) license, allowing to download articles and share them with others as long as they credit the authors and the publisher, but without permission to change them in any way or use them commercially. For commercial use, please contact the journal office at kardiologiapolska@ptkardio.pl.

How to cite: Grześkowiak M, Gaczkowska AD, Bekała A, et al. People, who survived their death. Advance for medical professionals based on the analysis of published cases worldwide. Kardiol Pol. 2021; 79(12): 1375-1377, doi: 10.33963/KP.a2021.0170.

\section{REFERENCES}

1. Wijdicks EFM, Diringer MN. Electrocardiographic activity after terminal cardiac arrest in neurocatastrophes. Neurology. 2004; 62(4): 673-674, doi: 10.1212/wnl.62.4.673, indexed in Pubmed: 14981200.

2. Linko K, Honkavaara P, Salmenpera M. Recovery after discontinued cardiopulmonary resuscitation. Lancet. 1982; 1(8263): 106-107, doi: 10.1016/s0140-6736(82)90242-2, indexed in Pubmed: 6119470.

3. Bray JG. The Lazarus phenomenon revisited. Anesthesiology. 1993; 78(5): 991, doi: 10.1097/00000542-199305000-00030, indexed in Pubmed: 8110211.

4. Hannig KE, Hauritz RW, Grove EL. Autoresuscitation: a case and discussion of the Lazarus phenomenon. Case Rep Med. 2015; 2015: 724174, doi: 10.1155/2015/724174, indexed in Pubmed: 26167181.

5. Hornby K, Hornby L, Shemie SD. A systematic review of autoresuscitation after cardiac arrest. Crit Care Med. 2010; 38(5): 1246-1253, doi: 10.1097/CCM.0b013e3181d8caaa, indexed in Pubmed: 20228683.

6. Hornby L, Dhanani S, Shemie SD. Update of a systematic review of autoresuscitation after cardiac arrest. Crit Care Med. 2018;46(3): e268-e272, doi: 10.1097/CCM.0000000000002920, indexed in Pubmed: 29286944.

7. Herff $H$, Loosen SJ, Paal $P$, et al. False positive death certification. Does the Lazarus phenomenon partly explain false positive death certification by rescue services in Germany, Austria and Switzerland? [In German]. Anaesthesist. 2010; 59(4): 342-346, doi: 10.1007/s00101-010-1710-1, indexed in Pubmed: 20224947.

8. Sheth KN, Nutter T, Stein DM, et al. Autoresuscitation after asystole in patients being considered for organ donation. Crit Care Med. 2012; 40(1): 158-161, doi: 10.1097/CCM.0b013e31822f0b2a, indexed in Pubmed: 21926577.

9. Yilmaz $S$, Omurlu IK. Survival after cardiopulmonary arrest in a tertiary care hospital in Turkey. Ann Saudi Med. 2019; 39(2): 92-99, doi: 10.5144/02564947.2019.07.03.1400, indexed in Pubmed: 30905924.

10. Walker A, McClelland $\mathrm{H}$, Brenchley J. The Lazarus phenomenon following recreational drug use. Emerg Med J. 2001; 18(1): 74-75, doi: 10.1136/emj.18.1.74, indexed in Pubmed: 11310473.

11. Ben-David B, Stonebraker VC, Hershman R, et al. Survival after failed intraoperative resuscitation: a case of "Lazarus syndrome". Anesth Analg. 2001;92(3):690-692, doi: 10.1097/00000539-200103000-00027, indexed in Pubmed: 11226103.

12. Ravipragasam S, Chandar D, Pandit V. Initial documented rhythm as a predictor of survivalto-discharge rate after in-hospital cardiac arrest in a tertiary care referral institute, South India: an observational study. Journal of Emergency Practice and Trauma. 2019; 6(1): 23-27, doi: 10.15171/jept.2019.23.

13. Kagawa E, Inoue I, Kawagoe T, et al. Assessment of outcomes and differences between in- and out-of-hospital cardiac arrest patients treated with cardiopulmonary resuscitation using extracorporeal life support. Resuscitation. 2010; 81(8): 968-973, doi: 10.1016/j.resuscitation.2010.03.037, indexed in Pubmed: 20627526.

14. Welbourn C, Efstathiou N. How does the length of cardiopulmonary resuscitation affect brain damage in patients surviving cardiac arrest? A systematic review. Scand J Trauma Resusc Emerg Med. 2018; 26(1): 77, doi: 10.1186/s13049-018-0476-3, indexed in Pubmed: 30201018.

15. Sip M, Puślecki M, Kłosiewicz T, et al. A concept for the development of a pioneer regional Out-of-Hospital Cardiac Arrest Program to improve patient outcomes. Kardiol Pol. 2020; 78(9):875-881, doi: 10.33963/KP.15433, indexed in Pubmed: 32550730. 